\title{
Effect of salbutamol on histamine induced bronchoconstriction in healthy infants
}

\author{
A J W Henderson, S Young, S M Stick, L I Landau, P N LeSouëf
}

\begin{abstract}
Background-The effect of inhaled $\beta_{2}$ adrenergic drugs on infants with wheezing disorders remains controversial. Salbutamol inhibits the bronchial responsiveness of infants to histamine and nebulised water but whether or not it acts as a bronchodilator in this age group is unclear. The aim of the present study was to determine whether salbutamol can hasten the reversal of histamine induced bronchoconstriction in infants.
\end{abstract}

Methods-Bronchial challenge with histamine was performed in 40 infants aged 12 months or less with no previous history of respiratory symptoms. Response to histamine was assessed by forced partial expiratory flow/volume curves to measure maximal flow at functional residual capacity ( $\max$ FRC). After a fall of $\mathbf{4 0 \%}$ or more from baseline VmaxFRC, each infant was randomly assigned to receive either salbutamol $0.5 \%$ or saline $0.9 \%$ solution by nebuliser. The rate of recovery of VmaxFRC and the time to reach baseline VmaxFRC were derived by linear regression.

Results-Infants who received salbutamol had a significantly faster rate of recovery (geometric mean $8.5 \mathrm{ml} / \mathrm{s} / \mathrm{min}$ ) than those who received saline $(4 \cdot 1 \mathrm{ml} / \mathrm{s} / \mathrm{min})$. Considerable interindividual variation was observed in the time from maximum bronchoconstriction to recovery of baseline VंmaxFRC in both groups of subjects. Conclusions-Salbutamol significantly speeds the reversal of histamine induced bronchoconstriction in infants during the first 12 months of life. This observation provides further evidence to support the presence of functional $\beta$ adrenergic receptors in the airways of infants.

(Thorax 1993;48:317-323)

The effect of inhaled $\beta_{2}$ adrenergic drugs on infants with wheezing disorders remains controversial with many studies showing no improvement in lung function,,$^{1-4}$ and others showing a decline in function..$^{5-7}$ The observed absence of a clear beneficial effect of $\beta_{2}$ agonists in wheezy infants is not explained by an absence of $\beta_{2}$ adrenergic receptors in the infant lung, as studies have shown a protective effect of inhaled salbutamol on histamine challenge $^{8}$ and nebulised water challenge ${ }^{9}$ in recurrently wheezy infants. A study by Tepper ${ }^{10}$ suggested a therapeutic effect of isoprenaline after methacholine challenge in healthy infants, but this evaluation was neither controlled nor randomised. Histamine and methacholine have different pharmacological effects on the airways ${ }^{11}$ and methacholine has been shown to provoke more central bronchoconstriction than the more peripheral action of histamine. ${ }^{12}$ Histamine and methacholine also induce different time courses of bronchoconstriction in adult subjects with more rapid recovery following histamine challenge. ${ }^{13}$ Recovery after histamine challenge in infants is also rapid but there is considerable intersubject variation. ${ }^{14}$ There is no clear information on the effect of inhaled salbutamol on histamine induced bronchoconstriction. This study was designed to test the hypothesis that, in infants during the first 12 months of life, inhaled salbutamol would lead to a more rapid recovery of baseline lung function after histamine induced bronchoconstriction.

\section{Methods}

Forty nine healthy infants taking part in a community based longitudinal survey of bronchial hyperresponsiveness were assessed. Forty (22 boys; age range 3-55 weeks) were identified who had a greater than $40 \%$ fall in VmaxFRC after histamine inhalation, and they were studied. The infants were all randomly recruited from a general antenatal clinic and none was symptomatic at the time of study or had a history of recurrent wheeze. Approval for the study was obtained from the Research and Ethics Committee of Princess Margaret Hospital for Children. Informed consent was obtained from the parents of each infant studied.

Respiratory function was assessed by forced partial expiratory flow/volume curves. ${ }^{15}$ The infants were given $80 \mathrm{mg} / \mathrm{kg}$ chloral hydrate and, once asleep, an inflatable jacket was wrapped around the chest and abdomen. The jacket was rapidly inflated at end inspiration and flow was measured at functional residual capacity (FRC). Inflation pressures of the jacket were gradually increased over a series of 
forced expirations until maximal flow at FRC (VmaxFRC) was obtained. Once this pressure had been established it was used for all forced expirations throughout that study. The infant breathed through a therapeutic putty face mask and flow was measured at the mouth with a Fleisch No. 1 pneumotachograph (P K Morgan Ltd, Chatham, UK) attached to a pressure transducer (Validyne DP45) and carrier amplifier (Validyne CD19; Validyne Co, California, USA). Volume was calculated by electronic integration of the flow signal. All data were recorded on a chart recorder (Polygraph WT-685G; Nihon Kohden Corporation, Tokyo, Japan). Flow and volume were displayed during the study on a digitising oscilloscope (Teknotronix 5223; Beaverton, Oregon, USA) and stored on magnetic tape (TEAC SR-50; TEAC Corporation, Tokyo, Japan). Taped data were transcribed to paper on an XY plotter (Hewlett Packard, Waltham, Massachusetts, USA). Arterial oxygen saturation $\left(\mathrm{SaO}_{2}\right)$ and pulse rate were monitored throughout the study with a pulse oximeter (Nellcor N-200E; Nellcor, Hayward, California, USA).

Histamine challenge tests were performed using methods described previously. ${ }^{1416}$ Nebulised normal saline was delivered from an Airlife Misty nebuliser (American Pharmaseal Co., Valencia, California, USA) with a flow rate of $6 \mathrm{1} / \mathrm{min}$ and inhaled by the infant by tidal breathing for one minute. The mean VmaxFRC of five forced partial expiratory flow/volume curves was measured after saline and taken as baseline VmaxFRC. Nebulised histamine was then administered in doubling concentrations from $0.125 \mathrm{~g} / 1$ to $8.0 \mathrm{~g} / 1$ at five minute intervals by the tidal breathing method. Five forced partial expiratory flow/volume curves were obtained after each concentration of histamine. The challenge was concluded when either a $40 \%$ fall occurred in VmaxFRC (greater than two standard deviations from the mean for this measurement) or when the maximum concentration of histamine was reached. The provoking concentration of histamine causing a $40 \%$ fall in VmaxFRC $\left(\mathbf{P C}_{40}\right)$ was determined by linear extrapolation of a log dose-response curve of histamine concentration against percentage fall from baseline VmaxFRC.

Note that the $\mathrm{PC}_{40}$ in the present study refers to the histamine concentration of the nebuliser solution rather than the inspired gas. It has recently been shown that, for comparison between infants, the concentration of histamine in the inhaled gas should be used to calculate $\mathrm{PC}_{40}$ to correct for air entrainment diluting histamine in the nebuliser output. ${ }^{17}$ We did not correct for air entrainment in the present study as the protocol did not involve intersubject comparison of $\mathrm{PC}_{40}$.

Infants who showed a response to histamine by a $40 \%$ or greater fall in VंmaxFRC before the maximum concentration of histamine was reached were eligible for the study. Measurement of VmaxFRC was repeated five minutes after the concentration of histamine which had provoked a $40 \%$ fall. If VmaxFRC was still $40 \%$ or more below baseline, the infant was randomised to receive either nebulised salbutamol or normal saline control. Randomisation was carried out before the study so that 20 infants each received salbutamol or saline. Treatment slips were sealed in opaque envelopes which were arranged in random order. A third party drew the top envelope at the start of the histamine challenge test and prepared either $2 \mathrm{ml} 0.9 \%$ saline or $2 \mathrm{ml}$ $0.5 \%$ salbutamol solution. The envelope was resealed and labelled with the infant's name and study number. The contents of the envelopes remained unknown to the principal investigators until all the studies were completed and their results calculated. Infants were given the nebulised therapy for one minute of tidal breathing during which the nebuliser delivers $0.3 \mathrm{ml}$ as determined by weight loss of the nebuliser. The mass of salbutamol nebulised was therefore $1.5 \mathrm{mg}$ for all infants. The concentration of salbutamol solution was chosen so that this mass could be delivered over a short time. If the nebulisation time was longer, recovery of $\dot{V} \operatorname{maxFRC}$ may have occurred during the administration of the inhaled therapy when lung function measurements could not be made.

Measurements of VंmaxFRC were repeated one minute after completion of the nebulised salbutamol or saline and then at five minute intervals until the infant woke or the measurement returned to its baseline value. Pulse rate and $\mathrm{SaO}_{2}$ were measured continuously and their values were recorded at the time of measuring $\dot{\text { maxFRC. }}$

\section{DATA ANALYSIS}

The indices of recovery analysed after histamine challenge were the rate of recovery and the time taken to reach baseline VmaxFRC. Methods of analysing serial data described by Matthews and colleagues ${ }^{18}$ were used to derive these variables. A linear regression was fitted to a plot of $\dot{\mathrm{V}}$ axFRC against time for each subject. The slope of the regression line was taken as the rate of recovery and its intercept with baseline VmaxFRC was taken as the time to recovery $\left(T_{r}\right)$. As the majority of infants woke before reaching baseline VmaxFRC it was necessary to extrapolate the regression line so that a value for $T_{r}$ was available for all infants studied.

The suitability of a linear model to explain the recovery of VmaxFRC was tested by calculating the coefficient of linear regression $(r)$ and the analysis of variance (ANOVA) of observed measurements from the fitted linear model for each subject. The mean $(95 \% \mathrm{CI})$ coefficient of linear regression for subjects who received salbutamol and whose results were based on three or more observations (15 subjects) was $r=0.87(0.78-0.96)$ and the goodness of fit was significant in every case (ANOVA, $p<0.01$ ). Infants who received saline and whose results were based on three or more observations (17 subjects) had a mean $(95 \% \mathrm{CI})$ coefficient of linear regression of $r=0.93(0.88-0.98)$ and the goodness of fit was significant in every case (ANOVA, 
Age, sex, baseline lung function, and $P C_{40}$ of 20 infants who received saline and 20 who received salbutamol after histamine challenge.

\begin{tabular}{|c|c|c|c|c|c|c|c|c|}
\hline \multirow[b]{2}{*}{ Subject } & \multicolumn{4}{|l|}{ Saline } & \multicolumn{4}{|c|}{ Salbutamol } \\
\hline & $\begin{array}{l}\text { Age } \\
\text { (wks) }\end{array}$ & Sex & $\begin{array}{l}\dot{V}_{(\%)} \max F R C \\
\end{array}$ & $\begin{array}{l}P C_{40} \\
(g / l)\end{array}$ & $\begin{array}{l}\text { Age } \\
\text { (wks) }\end{array}$ & Sex & $\underset{(\%)}{\dot{\max } F R C}$ & $\begin{array}{l}P C_{40} \\
(g / l)\end{array}$ \\
\hline 1 & 4 & $\mathbf{M}$ & 35.4 & 0.50 & 3 & $\mathbf{M}$ & $92 \cdot 9$ & $1 \cdot 54$ \\
\hline 2 & 4 & $\mathbf{M}$ & $124 \cdot 0$ & 0.80 & 3 & $\mathbf{M}$ & $88 \cdot 1$ & $7 \cdot 10$ \\
\hline 3 & 4 & $\mathbf{M}$ & $112 \cdot 2$ & $1 \cdot 00$ & 4 & $\mathbf{M}$ & $\star$ & $2 \cdot 24$ \\
\hline 4 & 4 & $\mathrm{~F}$ & $97 \cdot 7$ & $1 \cdot 12$ & 4 & $\mathbf{M}$ & $107 \cdot 5$ & 0.35 \\
\hline 5 & 4 & F & $133 \cdot 7$ & 0.62 & 4 & $\mathbf{M}$ & $179 \cdot 4$ & $2 \cdot 40$ \\
\hline 6 & 5 & $\mathbf{M}$ & $83 \cdot 2$ & $7 \cdot 10$ & 4 & $\mathbf{M}$ & 153.9 & 4.95 \\
\hline 7 & 5 & $\mathbf{M}$ & $90 \cdot 3$ & 0.50 & 5 & $M$ & $96 \cdot 7$ & $7 \cdot 80$ \\
\hline 8 & 5 & $\mathbf{F}$ & $75 \cdot 9$ & $3 \cdot 10$ & 6 & $M$ & $78 \cdot 3$ & $0 \cdot 20$ \\
\hline 9 & 5 & $\mathbf{F}$ & $75 \cdot 1$ & 0.50 & 6 & F & 162.5 & 0.88 \\
\hline 10 & 5 & $F$ & $56 \cdot 0$ & $1 \cdot 50$ & 8 & F & $62 \cdot 8$ & 1.50 \\
\hline 11 & 6 & $\mathrm{M}$ & 81.9 & $2 \cdot 80$ & 9 & M & $68 \cdot 8$ & 1.05 \\
\hline 12 & 7 & $\mathbf{M}$ & $88 \cdot 3$ & $3 \cdot 20$ & 20 & $\mathrm{~F}$ & $94 \cdot 1$ & $6 \cdot 22$ \\
\hline 13 & 7 & $\mathbf{M}$ & $46 \cdot 5$ & 1.63 & 25 & $\mathrm{~F}$ & $29 \cdot 9$ & 0.31 \\
\hline 14 & 7 & $\mathrm{~F}$ & $65 \cdot 2$ & 0.13 & 27 & $\mathbf{M}$ & $72 \cdot 9$ & $3 \cdot 25$ \\
\hline 15 & 24 & $\mathrm{~F}$ & $72 \cdot 3$ & $1 \cdot 54$ & 28 & $\mathbf{M}$ & 80.9 & $1 \cdot 48$ \\
\hline 16 & 25 & $\mathbf{M}$ & 133.9 & $0 \cdot 20$ & 30 & $\mathbf{M}$ & $49 \cdot 3$ & 1.05 \\
\hline 17 & 26 & F & $65 \cdot 6$ & $1 \cdot 87$ & 51 & F & $144 \cdot 7$ & 1.75 \\
\hline 18 & 54 & M & 92.9 & 0.64 & 51 & $\mathrm{~F}$ & $100 \cdot 0$ & 0.46 \\
\hline 19 & 54 & $\mathbf{F}$ & $184 \cdot 4$ & 0.78 & 53 & $F$ & $59 \cdot 7$ & $7 \cdot 25$ \\
\hline 20 & 54 & $\mathbf{F}$ & $114 \cdot 1$ & 2.00 & 55 & $\mathrm{~F}$ & $61 \cdot 8$ & 0.49 \\
\hline Median & $5 \cdot 5$ & & & & 8.5 & & & \\
\hline Mean & & & $91 \cdot 4$ & & & & 93.9 & \\
\hline Geometric & & & & & & & & \\
\hline mean & & & & $1 \cdot 04$ & & & & $1 \cdot 54$ \\
\hline
\end{tabular}

^Length not available (infant in splint).

VmaxFRC - maximum flow at functional residual capacity; $\mathrm{PC}_{40}$-provoking concentration of histamine causing a $40 \%$ fall in $\dot{\max } \mathrm{FRC}$.

$\mathrm{p}<0 \cdot 01)$. A linear model therefore was accepted as an appropriate approximation to the pattern of recovery of VmaxFRC after histamine induced bronchoconstriction in the majority of infants studied.

The slopes of the fitted linear regressions were normally distributed after logarithmic transformation and the geometric means were compared using Student's $t$ test. The values for $T_{r}$ were compared using the MannWhitney test. Differences in pulse rate and $\mathrm{SaO}_{2}$ from prenebulisation baseline values were normally distributed without transformation. Within group comparisons were made with paired $t$ tests. Other comparisons between groups of data were made with nonparametric tests. A probability of less than $5 \%$ was used to reject the null hypothesis that there was no difference between the groups in all analyses.

\section{Results}

Twenty infants received salbutamol after histamine challenge and 20 received normal saline. Their age, sex, baseline V̇maxFRC (as percentage predicted $)^{19}$ and $\mathrm{PC}_{40}(\mathrm{~g} / \mathrm{l})$ did not differ significantly (table). Mean (SD) baseline $\mathrm{SaO}_{2}$ (before histamine challenge) was $99.2(1 \cdot 1) \%$ in the saline treated infants and $99.1(0.9) \%$ in the salbutamol treated infants. After histamine challenge and before nebulised salbutamol or saline, measurements of $\mathrm{SaO}_{2}$ were not significantly different from baseline in either group, $98.6(2.0) \%$ and 98.9 $(1 \cdot 2) \%$ respectively.

After receiving nebulised salbutamol or saline VmaxFRC fell further by more than $10 \%$ (intrasubject coefficient of variation $9.5 \%)^{15}$ in 11 of the 40 subjects; eight after saline and three after salbutamol. The proportion of subjects experiencing a further decline in $V$ maxFRC after the nebulisation was significantly higher in the saline treated infants, $\left(p<0.05, \chi^{2}\right.$ test).

Changes in $\mathrm{SaO}_{2}$ from prenebulisation values after salbutamol and saline are shown in fig 1 and changes in pulse rate are shown in fig 2. Both substances provoked a significant fall in $\mathrm{SaO}_{2}$ with the reduction tending to be more prolonged in those infants treated with salbutamol although no significant differences were found between the groups. The pulse rate rose significantly after nebulised saline and salbutamol but in the saline treated subjects the rise was transient and the pulse rate

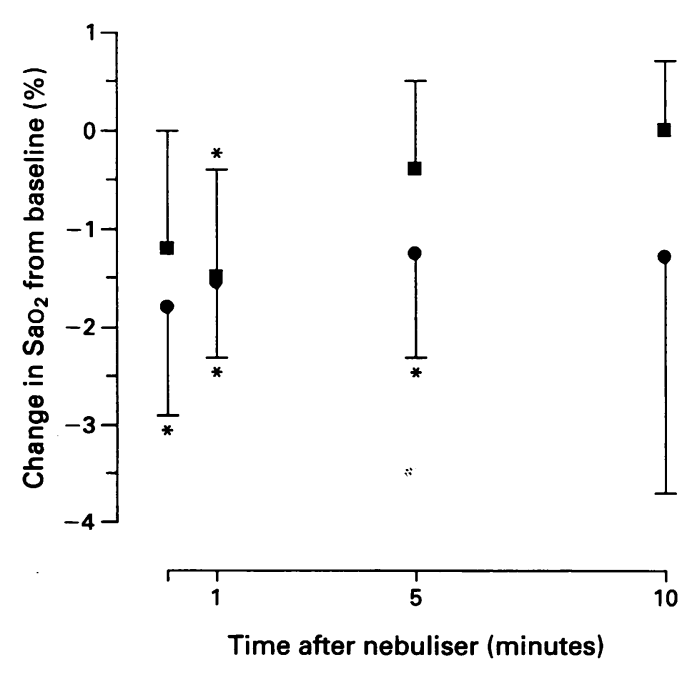

Figure 1 Mean $(95 \% \mathrm{CI})$ changes in $\mathrm{SaO}_{2}$ from prenebulisation baseline values for infants given saline (অ) and salbutamol (0) following histamine challenge. $\star$ Significant within group difference from baseline, $p<0.05$. 
Figure 2 Mean $195 \%$ CI) changes in pulse rate from prenebulisation baseline values for infants given saline ( $\mathbf{D}$ ) and salbutamol (O) following histamine challenge. *Significant within group difference from baseline, $p<0.05$; tsignificant between group difference, $p<0 \cdot 05$.

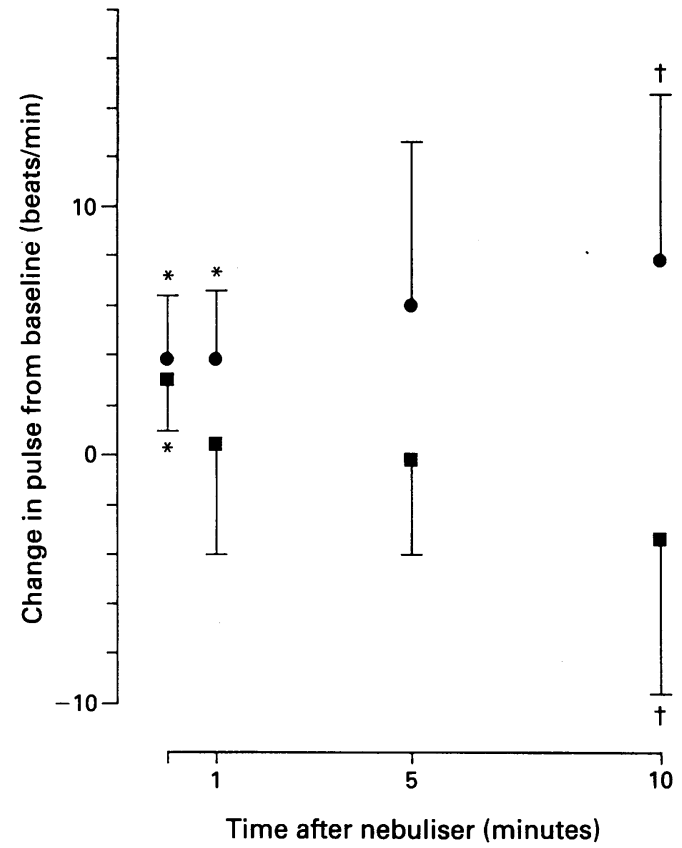

Saline
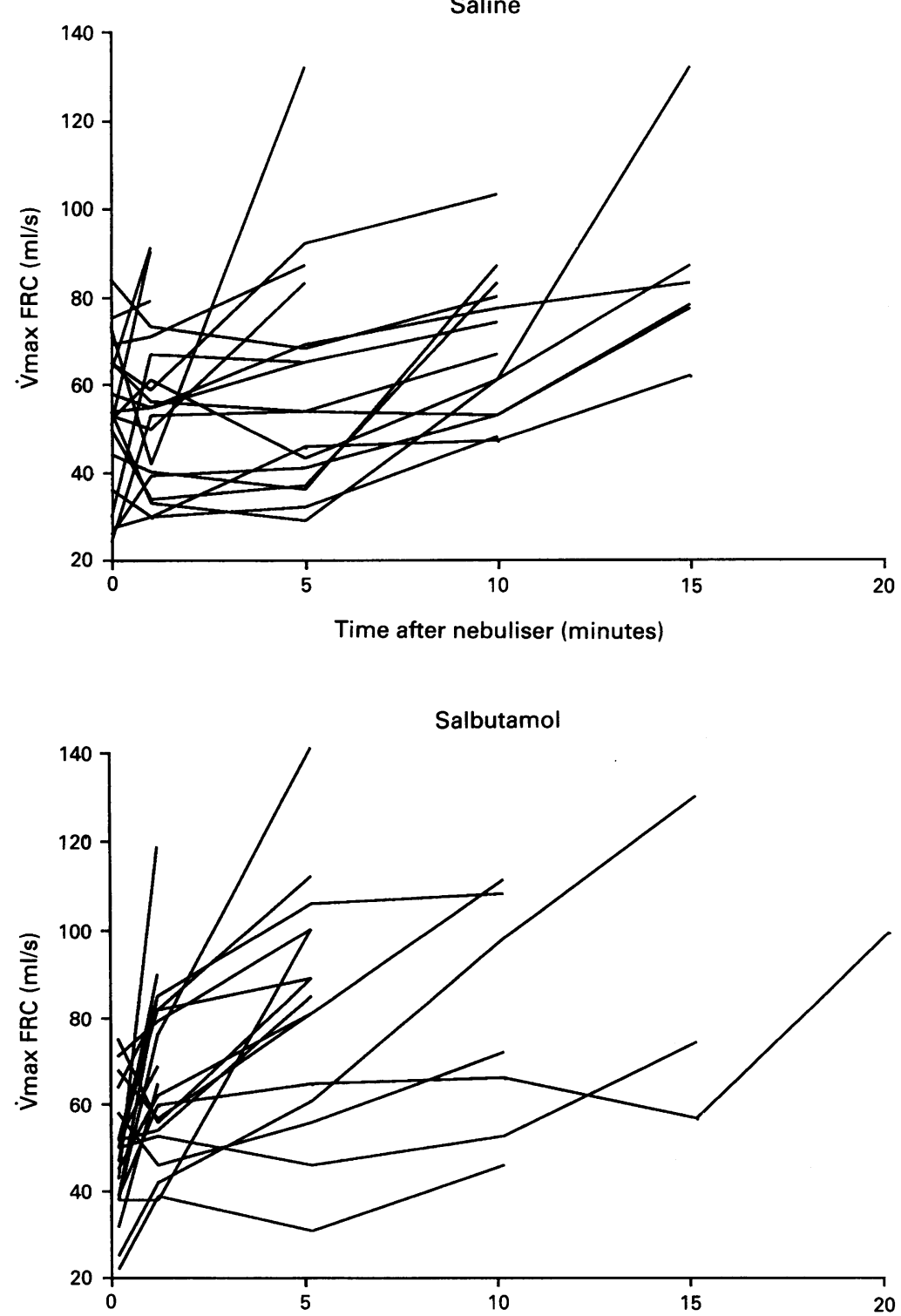

Figure 3 Actual recovery of VMaxFRC following histamine induced bronchoconstriction in 20 infants who received nebulised saline and 20 who received nebulised salbutamol. at one minute was not significantly higher than prenebulisation values. In the salbutamol treated infants the rise in pulse rate was sustained and the mean change at 10 minutes after nebulisation was significantly greater than that in the saline treated group (unpaired Student's $t$ test, $\mathrm{p}<0 \cdot 05$ ).

The recovery of VmaxFRC with time for individual subjects is shown in fig 3 and the slopes of recovery derived from linear regression of VmaxFRC against time and the intercepts with mean baseline $\dot{V} \max F R C$ are shown in fig 4 . The geometric mean $(95 \% \mathrm{CI})$ slope in the saline treated subjects was $4 \cdot 1$ $\mathrm{ml} / \mathrm{s} / \mathrm{min}(2 \cdot 7-6 \cdot 2 \mathrm{ml} / \mathrm{s} / \mathrm{min})$ which was significantly less than the slope of $8.5 \mathrm{ml} / \mathrm{s} / \mathrm{min}$ $(5 \cdot 0-14.7 \mathrm{ml} / \mathrm{s} / \mathrm{min})$ for the salbutamol treated subjects (Student's $t$ test, $\mathrm{p}<0.05$ ). There was a trend for median $T_{r}$ to be longer in the saline treated infants (14.0 minutes) than in those who received salbutamol ( $7 \cdot 6$ minutes) but the difference did not reach significance (Mann-Whitney U test). Fifteen subjects (six saline treated, nine salbutamol treated) reached their baseline VmaxFRC before waking. The median $T_{r}$ in this subgroup was 12.5 minutes for those treated with saline and $5 \cdot 0$ minutes for those treated with salbutamol but the difference was not significant (MannWhitney U test).

There were no significant correlations between the minimum VmaxFRC (percentage baseline) after histamine challenge and slope of recovery in either the saline treated (Spearman's rank correlation test, $r_{\mathrm{s}}=0.27$ ) or salbutamol treated $\left(r_{\mathrm{s}}=0.09\right)$ groups. Minimum VंmaxFRC correlated with $T_{r}$ in the saline treated subjects $\left(r_{\mathrm{s}}=0.51, \mathrm{p}<0.05\right)$ but not in those treated with salbutamol $\left(r_{\mathrm{s}}=0 \cdot 13\right)$.

There was a higher proportion of younger infants in the saline treated group than in the salbutamol group but no significant differences were observed in the slope of recovery or $T_{r}$ between infants younger than six months and those older than six months in either the saline or salbutamol treated group. The geometric mean (95\% CI) slope of recovery was $5.2 \mathrm{ml} / \mathrm{s} / \mathrm{min}(3.0-9.2 \mathrm{ml} / \mathrm{s} / \mathrm{min})$ in infants under 6 months who received saline and $12.8 \mathrm{ml} / \mathrm{s} / \mathrm{min}(5.7-28.8 \mathrm{ml} / \mathrm{s} / \mathrm{min})$ in those who received salbutamol (Student's $t$ test, $\mathrm{p}>0.05)$. For infants of six to 12 months the geometric mean $(95 \% \mathrm{CI})$ slope of recovery was $4.7 \mathrm{ml} / \mathrm{s} / \mathrm{min}(3.5-6.1 \mathrm{ml} / \mathrm{s} / \mathrm{min})$ in those receiving saline and $8.2 \mathrm{ml} / \mathrm{s} / \mathrm{min}$ $(5.3-12.6 \mathrm{ml} / \mathrm{s} / \mathrm{min})$ in those receiving salbutamol (Student's $t$ test, $\mathrm{p}=0 \cdot 05$ ).

\section{Discussion}

The results of the study show that salbutamol increases the rate of recovery of maximal expiratory flow rates after histamine induced bronchoconstriction in normal infants during the first year of life. This provides further evidence that infants in this age group have functional $\beta_{2}$ receptors in their airways.

Salbutamol was administered by nebulising $0.5 \%$ solution directly into a face mask which 

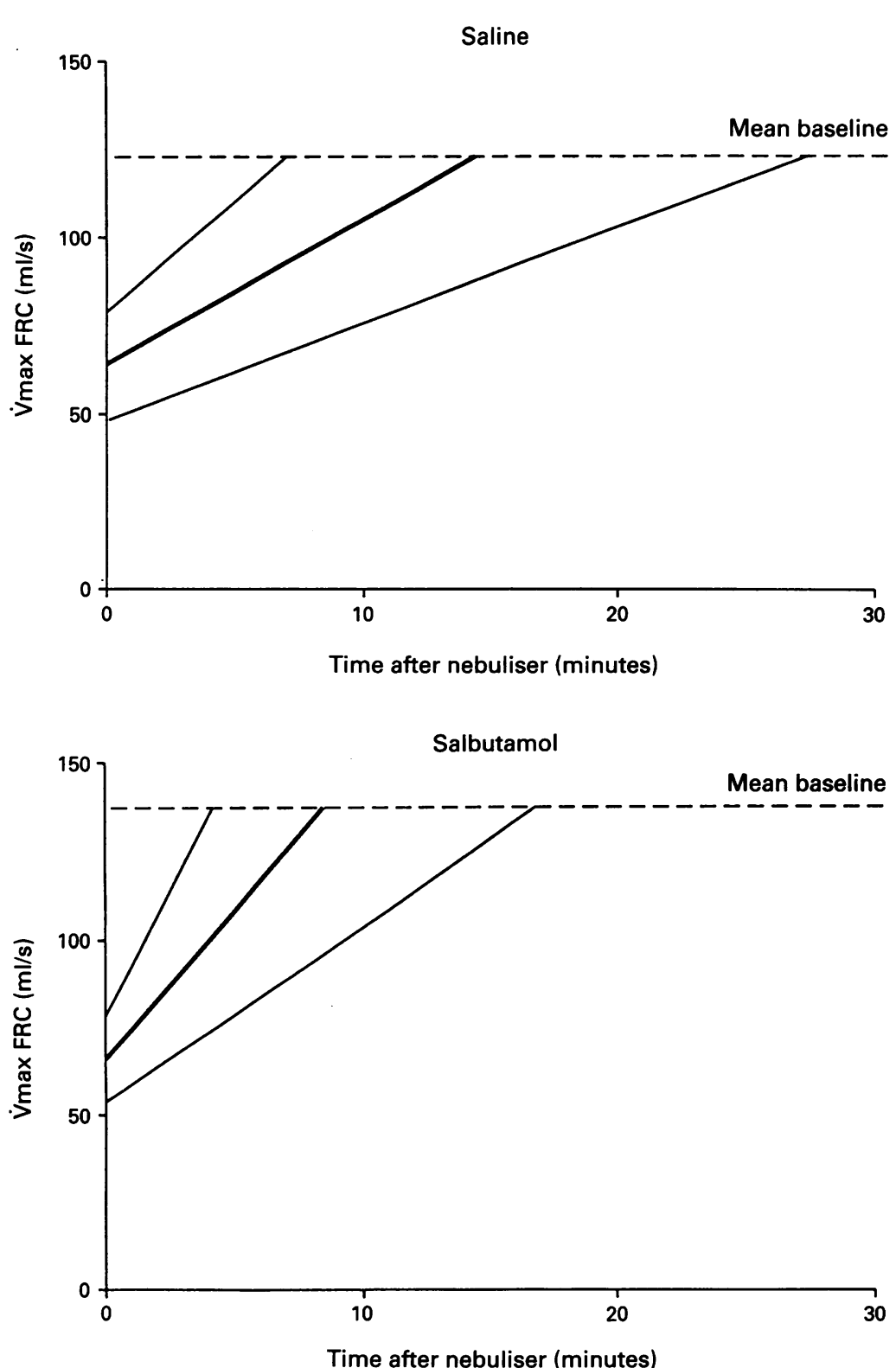

Figure 4 Recovery following histamine induced bronchoconstriction in infants who received saline or salbutamol. The mean (95\% CI) for VmaxFRC at time zero (immediately after saline/salbutamol) and the geometric mean (95\% CI) slope are shown for each group. be expected to produce lower percentage predicted values. The distribution of baseline V̇maxFRC may, however, simply reflect the heterogeneity of the measurement in an unselected population of asymptomatic infants. A similar wide distribution of percentage predicted VmaxFRC, independent of family history of asthma and parental smoking habit, has been shown previously in a large, randomly selected population of infants. ${ }^{20}$ In the present study the proportions of infants with low baseline VmaxFRC were similar in the two study groups and low baseline VmaxFRC, although associated with low $\mathrm{PC}_{40}$, was not related to the response to salbutamol. Low VmaxFRC in infancy may be associated with a greater risk of subsequent wheezing illness in children ${ }^{21}$ and may indicate those infants who will develop asthma. It seems unlikely, however, that our study was biased towards selecting infants at high risk of asthma or that the large number who appeared to respond to salbutamol after histamine induced bronchoconstriction were all at risk.

We used a linear model to calculate two indices of recovery after bronchoconstriction. Although the data do not necessarily recover in a true linear fashion (fig 3), the model explains a significant proportion of the variance of $\dot{V}$ maxFRC with time in every case and has the advantage of providing comparable results for all subjects. In our view the data are acceptably linear for this purpose and other methods such as extrapolation of the final two measurements of VmaxFRC before recovery are likely to be no more accurate. The times to recovery of infants who recovered baseline VmaxFRC before waking were similar to those predicted from the model, although there was no significant difference between the two groups.

A higher proportion of infants experienced a further fall in VmaxFRC after nebulisation of saline. If the regressions were to include baseline VmaxFRC in these cases, it is likely that the slopes of recovery would be lower and $T_{r}$ longer, thus exaggerating differences from the salbutamol treated group. Regressions were therefore made from minimum VmaxFRC after nebulisation, following which the linear model of recovery appeared to hold true.

We observed a small decrease in $\mathrm{SaO}_{2}$ after nebulisation of both saline and salbutamol. Prendiville and colleagues ${ }^{6}$ reported a decrease in transcutaneous $\mathrm{PaO}_{2}$ associated with decreased VmaxFRC following salbutamol in recurrently wheezy infants and suggested that this represented increased ventilation perfusion mismatch in these infants. Although no significant differences in $\mathrm{SaO}_{2}$ reduction were found between groups receiving salbutamol or saline in the present study of healthy infants, those given salbutamol tended to have a greater and more prolonged fall in $\mathrm{SaO}_{2}$.

It seems likely that the mechanism of airways obstruction after histamine challenge differs from that which occurs in the natural disease state in infants with recurrent wheeze. Prendiville and colleagues did not find a 
significant improvement in VmaxFRC after nebulised salbutamol in recurrently wheezy infants. ${ }^{6}$ This may be explained partly by differences in $\beta$ receptor density which has been shown in animal experiments to be reduced in bronchial smooth muscle in recurrently wheezy animals. ${ }^{22} 23$ The relatively fixed obstruction observed in recurrently wheezy infants $^{6}$ may also lead to mechanical differences in the airways compared with those which follow histamine challenge. Airway inflammation with widespread peripheral narrowing may contribute to increased dynamic compression during forced expiration ${ }^{24}$ and reduced maximal expiratory flow. Stimulation of $\beta$ adrenergic receptors may lead to a reduction in airway tone which could result in greater flow limitation than any increase in airway calibre resulting from smooth muscle relaxation. The more rapid improvement in maximal expiratory flow in normal infants receiving salbutamol than in those receiving saline could be explained by the advantages of smooth muscle relaxation and reduced mucosal oedema. Any reduction in airway tone would be less disadvantageous in this population with little or no fixed peripheral airway narrowing and therefore less likely to have widespread dynamic compression.

The effect of histamine on the airways is mediated by several different pathways; direct receptor mediated actions on airway smooth muscle, and stimulation of central and local neural reflexes. ${ }^{11}$ The time course of bronchoconstriction after histamine has been studied in adults ${ }^{13}$ in whom the mean rate of recovery was $2 \cdot 43 \%$ of baseline lung resistance/minute with a mean recovery time of 25.5 minutes. This compares with a recovery rate of $3.3 \%$ baseline $\operatorname{VmaxFRC/minute}$ and a median time to recovery of 19.0 minutes in the control population in the present study (14.0 minutes after saline nebulisation plus 5.0 minutes after previous concentration of histamine). The similarities in time courses are likely to correspond to similar pathophysiological changes in the lungs after histamine challenge in infants and adults. Salbutamol relieves airway obstruction in adults with asthma, however, but has little or no effect on lung function in infants with bronchiolitis or recurrent wheeze. ${ }^{1-4}$ It seems likely, therefore, that airway obstruction in these conditions differs from that occurring in adult asthma or after histamine challenge. Attention has recently focused on the role of microvascular leakage leading to airway wall oedema in the aetiology of asthma. ${ }^{25}$ The smaller airways of infants are likely to be more readily obstructed by airway wall oedema ${ }^{26}$ and this may be a more important mechanism than smooth muscle constriction in causing airway obstruction in this age group. Although $\beta$ adrenergic agonists may have an inhibitory effect on microvascular permeability, ${ }^{25}$ salbutamol has been shown to have no effect on plasma leakage induced by platelet aggregating factor in animals. ${ }^{27}$ The probable differences in the mechanisms of acute mucosal changes in the airways after histamine challenge and the chronic mucosal changes associated with recurrent wheeze in infancy may therefore give rise to differences in pharmacological response even though the initial degree of airway obstruction is similar.

Our data suggest that functional $\beta$ adrenergic receptors are present in the lungs of normal, healthy infants and that stimulation of these receptors with the $\beta_{2}$ adrenergic agonist salbutamol leads to more rapid recovery from histamine induced bronchoconstriction than saline controls. The histamine challenge test is a useful tool for the study of bronchial responsiveness in adults and children, but the results of this study suggest that the pathophysiology of histamine induced airway obstruction in infants is likely to be different from the airway obstruction which occurs with acute bronchiolitis or recurrent wheeze in this age group. A J W Henderson was recipient of a Royal College of
Physicians of Edinburgh/Glaxo Travelling Fellowship. The authors are grateful to D J Turner, J Arnott and G Collis for technical assistance with this study.

1 Phelan PD, Williams HE. Sympathomimetic drugs in acute viral bronchiolitis. Pediatrics 1969;44:493-7.

2 Rutter N, Milner AD, Hiller EJ. Effect of bronchodilators on respiratory resistance in infants and young children with bronchiolitis and wheezy bronchitis. Arch Dis Child 1975;50:719-22.

3 Lenney W, Milner AD. At what age do bronchodilator drugs work? Arch Dis Child 1978;53:532-5.

4 Stokes GM, Milner AD, Hodges IGC, Henry RL, Elphick MC. Nebulised therapy in acute severe bronchiolitis in infancy. Arch Dis Child 1983;58:279-83.

5 O'Callaghan C, Milner AD, Swarbrick A. Paradoxical deterioration in lung function after nebulised salbutamol in wheezy infants. Lancet 1986;ii:1424-5.

6 Prendiville A, Green S, Silverman M. Paradoxical response to nebulised salbutamol in wheezy infants. Thorax 1987;42:86-91.

7 Hughes DM, LeSouëf PN, Landau LI. Effect of salbuta$\mathrm{mol}$ on respiratory mechanics in bronchiolitis. Pediat Res 1987;22:83-6.

8 Prendiville A, Green S, Silverman M. Airway responsiveness in wheezy infants: evidence for functional $\beta$ adrenergic receptors. Thorax 1987;42:100-4.

9 O'Callaghan C, Milner AD, Swarbrick A. Nebulised salbutamol does have a protective effect on airways in
children under one year old. Arch Dis Child 1988; 63:479-83.

10 Tepper RS. Airway reactivity in infants: a positive response to methacholine and metaproterenol. I Appl Physiol 1987;62:1155-9.

11 Holgate ST, Beardsley R, Twentyman OP. The pathogenesis and significance of bronchial hyperresponsiveness in airways disease. Clin Sci 1987;73:561-72.

12 Sezikawa K, Yanai M, Shimizu Y, Sasaki H, Takishima T. Serial distribution of bronchoconstriction in normal subjects. Am Rev Respir Dis 1988;137:1312-16.

13 Cartier A, Malo J-L, Begin P, Sestier M, Martin RM. Time course of the bronchoconstriction induced by inhaled histamine and methacholine. $f$ Appl Physiol 1983;54:821-6.

14 Prendiville A, Green S, Silverman M. Bronchial responsiveness to histamine in wheezy infants. Thorax 1987; 42:92-9.

15 Taussig LM, Landau LI, Godfrey S, Arad I. Determinants of forced expiratory flows in newborn infants. $f$ Appl Physiol 1982;53:1220-7.

16 LeSouëf PN, Geelhoed GC, Turner DJ, Morgan SEG, Landau LI. Response of normal infants to inhaled histamine. Am Rev Respir Dis 1989;139:62-6.

17 Collis GG, Cole CH, LeSouëf PN. Dilution of nebulised aerosols by air entrainment in children. Lancet 1990; 336:341-3.

18 Matthews JNS, Altman DG, Campbell MJ, Royston P. Analysis of serial measurements in medical research. BMF 1990;300:230-5.

19 Tepper RS, Morgan WJ, Cota K, Wright A, Taussig LM. Physiologic growth and development of the lung during the first year of life. Am Rev Respir Dis 1986;134:513-19.

20 Young S, LeSouëf PN, Geelhoed GC, Stick SM, Turner $\mathrm{KJ}$, Landau LI. The influence of a family history of asthma and parental smoking on airway responsiveness in early life. N Engl f Med 1991;324:1168-73. 
21 Martinez FD, Morgan WJ, Wright AL, Holberg CJ, Taussig LM. Diminished lung function as a predisposing factor for wheezing respiratory illness in infants. NEngl f Med 1988;319:1112-17.

22 Barnes PJ, Dollery CT, MacDermot J. Increased pulmonary alpha-adrenergic and reduced beta-adrenergic receptors in experimental asthma. Nature 1980;285: 569-71.

23 Jian-Ying $M$, She $B$. The distribution of beta-adrenergic receptors in guinea pig lungs and their changes in experimental allergic asthma. Sci China 1989;32:1208-14.
24 Bouhuys A, van de Woestijne KP. Mechanical consequences of smooth muscle relaxation. $\mathcal{f}$ Appl Physiol 1971;30:670-6.

25 Chung KF, Rogers DF, Barnes PJ, Evans TW. The role of airway microvascular permeability and plasma exudation in asthma. Eur Respir $\mathcal{F} 1990 ; 3: 329-37$.

26 Silverman M. Bronchodilators for wheezy infants? Arch Dis Child 1984;59:84-7.

27 Boschetto P, Roberts NM, Rogers DF, Barnes PJ. Effect of antiasthma drugs on microvascular leakage in guinea pig airways. Am Rev Respir Dis 1989;139:416-21.

\section{Clinical chest radiology}

Is the chest radiograph a special investigation or is it part of the clinical examination of the patient? It is my belief that it is the latter. As medical students we were taught that one should examine the patient first, make a provisional diagnosis, and then request the appropriate investigations, and for the most part, in the interest of financial and radiation economy, this must still be a guiding principle of diagnosis. In the practice of respiratory medicine, however, the plain chest radiograph is frequently the lynchpin of diagnosis, whether it be normal or abnormal. It was with some surprise that, as a thoracic house surgeon at Guy's Hospital, my "chief", Lord Brock, taught me to look at the chest radiograph first, then take the history and examine the patient, and finally go back to look at the radiograph. This fusion of the clinical approach and a basic investigation is an essential part of respiratory medicine. The place for the chest radiograph is in the ward at the bedside and not, as is the practice in many countries, including the USA, in the $x$ ray department on the other side of the hospital.

There are pitfalls to this approach for we may be too greatly influenced by our preconceived ideas. As a house physician at the Brompton Hospital in the 1950 s it was one of our duties to sit in a small cubicle in the outpatients department to take and record the clinical histories of the new patients attending the clinic. On one such day I had taken the histories of a Mr Brown, who was suffering from chronic bronchitis, and from a Mr Smith, who had for many years had pulmonary tuberculosis treated by a right sided artificial pneumothorax which had become infected. Mr Brown's chest radiograph was normal but that of $\mathrm{Mr}$ Smith showed a shrunken right lung with thickened and heavily calcified overlying pleura. When I had completed all the history taking I joined the consultant to whom I was attached for teaching. This eminent physician was examining Mr Brown's chest but, unfortunately, the nurse had inadvertently put $\mathrm{Mr}$ Smith's radiograph on the viewing box. I entered the room just as the consultant was saying "Yes, there is definite dullness at the right base with diminished air entry, and I detect reduction in movement of the whole of the right side."

Interpretation of the radiograph can also be overinfluenced by the clinical findings. Dullness and loss of air entry is not always the result of fluid, and I recall several patients who, after several attempted aspirations, have been found to have large diaphragmatic hernias and not fluid. Immediate provision of the film on the ward or in the outpatient clinic can cause some logistic problems for radiologists in providing a reporting service. Perhaps we should have peripatetic radiologists reporting the films on the wards, a practice which would enable better contact with clinical colleagues. As an example of this, for the past two years a radiologist has visited the intensive care unit at the Royal Brompton Hospital daily to review with the clinicians all the radiographs which are taken immediately to the unit before reporting.

IAN H KERR 